\title{
Comparison of Cutting Performance Durning Turning of Hardened Aisi 4340 Steel with Minimal Multiple Jet Cutting Fluid
}

\author{
Prof B.winston Sandeep kumar, Prof A.Sengole rayan \\ SRM UNIVERSITY (vadapalani campus)
}

\begin{abstract}
This project mainly concern with the minimal quantity lubricant used in metal cutting process during turning operation. New cutting techniques are to be investigating to achieve this objective. Hard turning with minimal fluid application is one such technique, which can ease the pollution problems associated with cutting fluids. In this project specially formulated cutting fluid is applied at high velocity, thin pulsed multiple jet form at the immediate cutting zones at extremely low rate of $5 \mathrm{ml} / \mathrm{min}$. Objective of this project is to enhance the performance of conventional hard turning by the application of minimal multiple jet of cutting fluid and compare it with conventional wet and pure dry cutting with respect to surface finish, tool wear and tool life.
\end{abstract}

\section{Introduction}

Recently, the concept of hard turning has gained considerable attention in metal cutting as it can apparently replace the traditional process cycle of turning, heat treating, and finish grinding for assembly of hard wear resistant steel parts. Hard turning can possibly facilitate low process cost, low process time, better surface quality, and lower waste.

Generally, hard turning necessitates the use of very rigid and precise machine tools and superior cutting tools such as CBN and ceramics tools. It may also need large quantities of cutting fluids to dissipate the heat generated. Further, the cutting fluid should be compatible with the machining process, machine tool and shop environment. In discriminate the use of cutting fluids can damage machine parts. In industrially developed countries, stringent health and safety regulations are enforced and according to the regulations of occupational safety and health administration (OSHA) of the USA, the permissible exposure level (PEL) of mist inside the plant is $5 \mathrm{mg} / \mathrm{m}^{3}$ and is likely to be reduced to $0.5 \mathrm{mg} / \mathrm{m}^{3}$. There are also regulations limiting the levels of pollutants in the spent metal working fluids which drastically increases the cost of disposal, totally dry turning may appear as a logical alternative .Under the circumstances, the concept of hard turning with minimal application of cutting fluid (HTMF) could be an alternative. In this method, extremely small quantities of cutting fluids are used and for all practical purposes, it resembles dry turning devoid of its main draw backs.

Investigations carried out in this area indicated that apart from conventional operating parameters, such as cutting velocity, feed and depth of cut, cutting fluid parameters namely, its composition and mode of delivery can also influence cutting performance.

\subsection{AIM OF THE PROJECT}

The project aims at finding out the optimal conditions for the optimal parameters such as cutting velocity, feed, depth of cut, and direction of application of coolant by following Taguchi's design of experiment. In this project 18 trials of experiments are estimated to be conducted on AISI 4340 material and the required parameters are to be measured. The dry turning is also compared in this work.

\subsection{SCOPE OF THE PROJECT}

In this project, optimization of process parameters of AISI 4340 material can be found and the effects of MQL in hard turning will be useful for the manufacturers to adapt this technology. Tests results can reveal most optimum conditions in hard turning.

\subsection{MINIMAL QUANTITY LUBRICATION}

Minimal quantity lubrication is a recent technique introduced in machining (in particular, in drilling) to obtain safe, environmental and economic benefits, reducing the use of coolant lubricant fluids in metal cutting. As reported by some authors, metal-working fluids cost ranges from 7 to $17 \%$ of the total machining cost, while the tool cost ranges from 2 to $4 \%$. Therefore, using MQL technique, a remarkable reduction of machining costs can be obtained reducing the quantity of lubricant used in machining. In MQL, a very small lubricant flow $(\mathrm{ml} / \mathrm{h}$ instead of $1 / \mathrm{min}$ ) is used. First of all it is necessary to mix air and lubricant to obtain the mixture to be spread on the cutting surface. Two different mixing methods can be used: mixing inside nozzle and mixing outside nozzle. 
Using the mixing inside nozzle equipment, pressurized air and lubricant are mixed into the nozzle by a mixing device, as shown. The lubrication is obtained by the lubricant, while a minimal cooling action is achieved by the pressurized air that reaches the cutting surface.

\subsection{CUTTING TOOLS FOR HARD TURNING}

Ceramic and CBN tools are widely used for hard turning in dry condition. There also reports of the use of coated tools in accompaniment of cutting fluids for accomplishing hard turning as reported in the following sections.

\section{A) Ceramic tools:}

The tool uses of alumina of very high purity $(99.99 \%)$ and grain size $0.22 \mu \mathrm{m}$ with practically no binder and sintered at a low temp. it is reported that this new alumina ceramic tool was found to be more wear resistant and fracture resistant against both mechanical and thermal shocks than conventional alumina tool.

B) CBN tools:

CBN tools is the deciding the wear character tics of CBN tools, which are widely used in turning of hardened steel .It is reported that ceramic bound CBN tools should excellent performance in machining hardened tool steel, case hardened steel etc. The cutting temp of the CBN tools was found to be lower than that of carbide tools and it decreased with the increase of work piece hardness. When the hardness exceed a control limit.

\section{C) Coated tools:}

The technique of magnetron sputtering can be effectively used for providing numerous layers with unique properties of nano structure namely high hardness, high strength, high modular, high wear resistance, high fracture toughness, high chemical stability and reduce friction [3].

\subsection{CUTTING FLUIDS IN METAL CUTTING}

Cutting fluid acts effectively as a lubricant at relatively low cutting speeds and as a coolant at high cutting speeds.

\section{ADVANTAGE:}

a) An increase tool life is achieved due to the reduction in the temp at the contact zone.

b) Cooling lowers the temp of the work piece there by protecting it from thermal distortions and also facilities easy handling of work pieces.

In any metal cutting operation, lot of heat is dissipated due to

* Plastic deformation of metals,

* Friction at the rake face of the tool between the tool and the chip

* Friction between the work piece and the flank of the tool

This increases the temperature both of the work piece and the tool point, resulting in decrease in hardness and hence life of the tool. The machined surface will also be rough and the possibility of BUE (Built up Edge) increases.

Heat is generated as a result of work done in cutting metals. This heat reduces the hardness of the cutting tool, makes it less wear resistant and changes its dimensions. Heat also leads to changes in the dimensions of machined surfaces. These temperature cause deformation of the tool and work reduce the machining accuracy.

Heat is carried away from the tool and work by means of cutting fluids which at the same time, reduce the friction between the tool and chip and between the tool and work and facilitate chip formation. So, the use of a cutting fluid during a machining operation is very essential. Its application at the tool-work interface produces the following effects [4].

\subsection{CHIP FORMATION DURING TURNING}

The form of chips produced is one of the major parameters influencing the productivity of metal cutting industry. Control over chip breaking is essential in unattended manufacture to ensure reliable and safe machining. Shape of the chip produced depending upon the machining conditions, the materials involved and the geometry of the cutting tool.

Based on the convenience of handling there are two types of chip forms,

1. Acceptable chips.

2. Unacceptable chips. 
Acceptable chips do not interfere with the work or machine tool and do not cause problem of disposal whereas unacceptable chips interrupt the regular cutting operation as they tend to entangle around the tool and the work piece and cause safety problems to operator.

Ribbon chips, tangled chips and corkscrew chips are difficult to handle. Such chips do not break on their own. They severely interfere with the work, the cutting tool and the machine tool. They come under the category of unacceptable chips.

Short tubular chips, spiral tubular chips and spiral chips are rated good from the point of view of ease of chip forming. Spiral and long tubular chips are acceptable if they are of short lengths. Arc chips and loose arc chips are acceptable if they do not influence the dynamic behavior of the machine tool. [2]

\subsection{MECHANISM OF CHIP FORMATION}

Normally the chip formed is unstable and varies even when the cutting conditions are kept identical. This is mainly due to the transient phenomenon such as the variation of the coefficient of friction between the tool and the chip, variation of temperature and variation of tool geometry due to the progression of the tool wear and non uniformity of the work material. The reduction of the coefficient of friction causes the formation of thinner chips, which curl more tightly. Additives such as $\mathrm{S}$ and $\mathrm{Pb}$ tend to reduce the length of chip formed by increasing its tendency to fracture. The formation of chip during metal cutting is governed by the direction in which the chip leaves the shear zone as determined by the chip flow angle and the curvature of the chip as decided by the nature of contact between the chip and tool. The chip is broken when the strain on it exceeds the fracture strain due to the presence of obstacles such as work piece or the cutting tool.

The factors such as tool wear, work piece in homogeneity and fluctuations in the dynamic behavior of the machine tool can also cause changes in the chip form during machining. [5]

\subsection{EFECTS ON TOOL WEAR}

During cutting operations one of the most important problems in tool wear, caused by the normal load generated by the relative motion between tool and chip and work piece and tool. Tool wear, which results in tool substitution, is one of the most important economical penalties to take in to account during cutting, so it is very important to improve tool life, minimizing the wear.

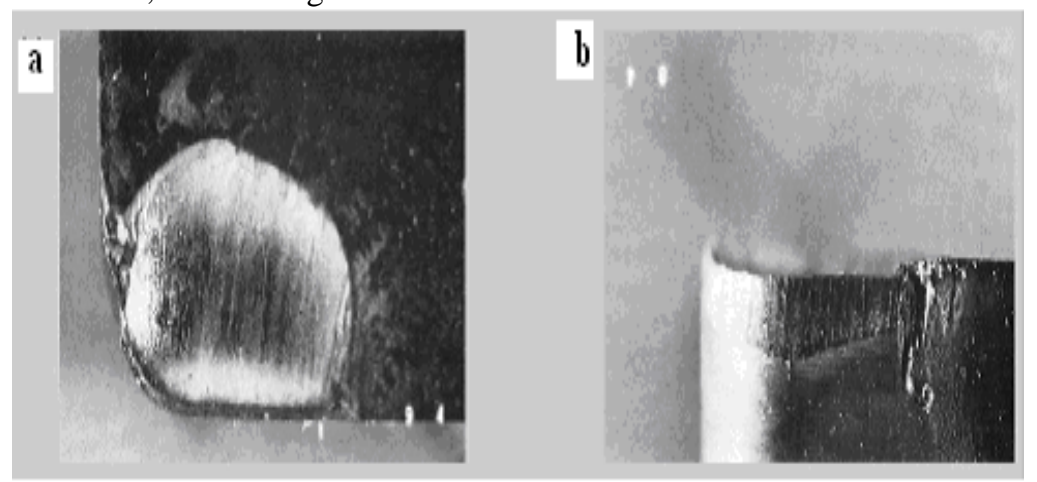

Fig 2.1 (a) Crater wear and (b) flank wear on a carbide tool.

As far as lubricant is concerned, the load applied and the working conditions, which characterize the cut, suggest that it is impossible continuously to lubricate the cutting area by fluid film lubrication. So, to guarantee lubrication, it is necessary to use lubricant with additives that chemically react with the work piece and tool material to generate chemical compounds that allow the lubrication of the cutting surface. More over, the work piece cooling is necessary to remove the heat generated during the chip formation and by the friction between tool and work Piece. [6]. To reach the cutting surface is not easy, in fact the high cutting pressure in the contact area and the small space between chip and tool do not allow the cutting fluid to access zone.

MQL applied on the rake surface, lubricant does not reach the cutting area. Lubricating the flank surface of the tip by the MQL technique reduces the tool wear and increase tool life. [6].

\subsection{REBINDER EFFECT}

During the application of cutting fluid in tool work interface, there is also the possibility of some (5 $\mathrm{ml} / \mathrm{min}$ ) tiny fluid particles reaching the uncut work surface near the cutting edge. These particles owing to their high velocity and smaller physical size can penetrate and firmly adhere to the work surface resulting in the promotion of plastic flow backside of the chip due to rebinder effect. 
Reduction on tool chip contact length reduces cutting force. Low cutting force leads to reduction in cutting temp there by reducing tool wear and reduced tool wear helps in maintaining better surface finish for a longer period of time. It promotes good chip curl [7].

\subsection{CHEMO -MECHANICAL EFFECT}

1) Chemo-micro weldment

2) Mechanical-cool the surface

The presence of cutting fluid on the cracks on top side of the chip causes weakening of the chip by preventing micro weldments at the tip of the crack. Cooling the top side of the chip due to the presence of cutting fluid .Result is the contraction of the top surface leading to the chip curl that causes reduction in tool chip contact length. [7].

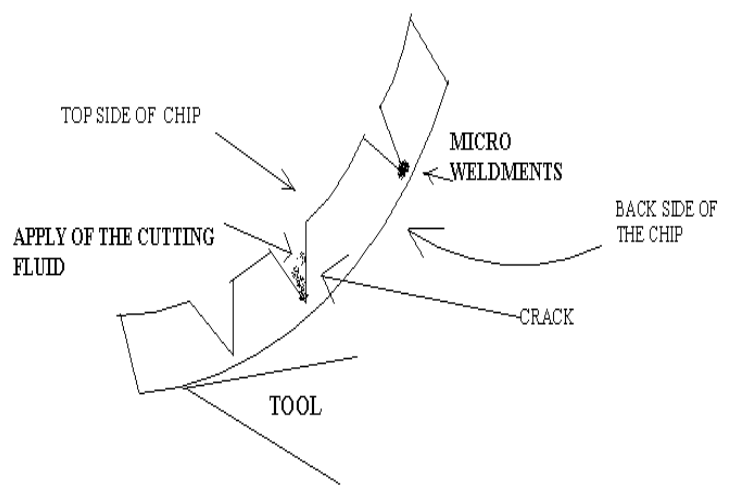

Fig 2.2 Crack arrested on the chip

\subsection{SELECTION OF WORK MATERIAL}

\section{Experimental Investigation}

The work material was a through hardenable steel (AISI 4340) which was hardened to 46 HRC (460 HV) by heat treatment. It is general-purpose steel having a wide range of application in automobile and allied industries by virtue of its good hardenability enabling it to be used in fairly large sections. Bars of $75 \mathrm{~mm}$ diameter and $320 \mathrm{~mm}$ length were used in the present experiment.

\subsection{SELECTION OF CUTTING TOOL}

Based on their easy availability and widespread use multicoated hard metal inserts with sculptured rake face geometry with the general specification, SNMG 120408 with a P30 or equivalent substrate with TiC, TiN and TiCN coatings from SANDVIK, Sweden were used in the present study. The tool holder used from the same source had the specification PSBNR 2525 M12.
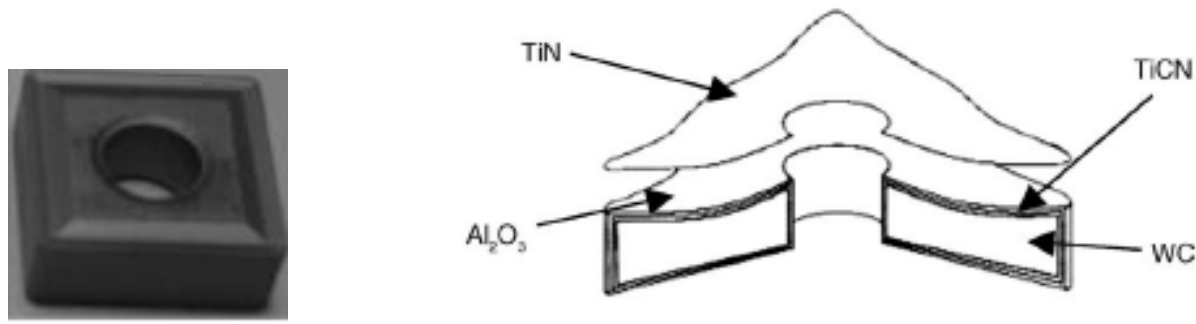

Fig 4.1 Cross sectional view of cutting tool

\subsection{FORMULATION OF CUTTING FLUID}

Since the quantity of cutting fluid used is extremely low in this new method, specially formulated cutting fluids with appropriate ingredients and properties were used in the present investigation. The base was a commercially available mineral oil. The formulation contained, in addition to coolant and lubricant, additives such as surfactant, evaporator, emulsifier, stabilizer, biocide and a deodorizing agent. 
Table 4.1 Cutting Fluid Compositions

\begin{tabular}{|l|l|l|}
\hline No. & Name of the constituent & Percentage \\
\hline 1. & Petroleum sulfonate (molecular weight=450 to 470) & $15 \%$ \\
\hline 2. & Ethylene glycol & $1 \%$ \\
\hline 3. & Oleic acid & $3 \%$ \\
\hline 4. & Triethaol amine & $3 \%$ \\
\hline 5. & Alcohol Ethoxylate & $2 \%$ to $6 \%$ \\
\hline 6. & Mineral oil (Paraffinic) & The rest \\
\hline
\end{tabular}

\subsection{FLUID APPLICATION SYSTEM COMPONENTS}

The components of fluid application system are as follows

1. DC shunt motor

2. Fuel Injection pump

3. Flexible coupling

4. storage tank

5. Injector

6. Copper tubes

7. Control unit

8. Frame

\subsubsection{SHUNT MOTOR WORKING PRINCIPLE:}

D.C. motors are motors that run on Direct Current from a battery or D.C. power supply. Direct Current is the term used to describe electricity at a constant voltage. When a battery or D.C. power supply is connected between a D.C. motor's electrical leads, the motor converts electrical energy to mechanical work as the output shaft turns. When a permanent magnet is positioned around a loop of wire that is hooked up to a D.C. power source, we have the basics of a D.C. motor. In order to make the loop of wire spin, we have to connect a battery or DC power supply between its ends, and support it so it can spin about its axis. To allow the rotor to turn without twisting the wires, the ends of the wire loop are connected to a set of contacts called the commutator, which rubs against a set of conductors called the brushes. The brushes make electrical contact with the commutator as it spins, and are connected to the positive and negative leads of the power source, allowing electricity to flow through the loop. The electricity flowing through the loop creates a magnetic field that interacts with the magnetic field of the permanent magnet to make the loop spin.

The shunt motor is different from the series motor in that the field winding is connected in parallel with the armature instead of in series. As per basic electrical theory a parallel circuit is often referred to as a shunt. Since the field winding is placed in parallel with the armature, it is called a shunt winding and the motor is called a shunt motor. Fig shows a diagram of a shunt motor. Notice that the field terminals are marked $\mathrm{Fl}$ and $\mathrm{F} 2$, and the armature terminals are marked $\mathrm{Al}$ andA2. You should notice in this diagram that the shunt field is represented with multiple turns using a thin line.

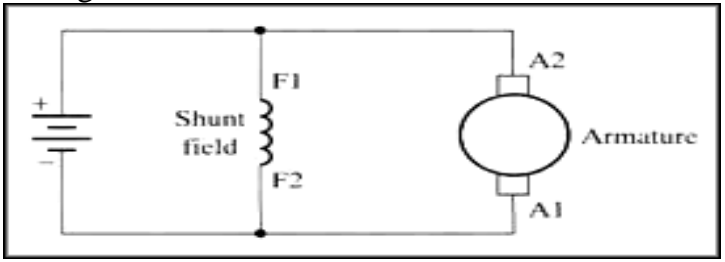

Fig4.5 Diagram of DC shunt motor 


\subsubsection{WORKING PRINCIPLE OF FUEL INJECTION PUMP}

The component which controls the quantity of fuel injected is element. The element consists of a plunger and a barrel. The barrel has an intake port and a spill (or return) port. The plunger has two types of motions. Reciprocating motion of the plunger is used to pressurize the fuel to the required pressure. The plunger has a helix groove. The rotary motion of the plunger determines at what time the helix should open against the spill port to by pass the fuel. This rotary motion determines the amount of fuel injected by increasing or decreasing the effective stroke, shows the operation fuel injection pump operation at different load conditions.

An overall view of the special test rig developed for injecting the cutting fluid is presented in Fig. and a more localized one in Fig. It consisted of a P-6 Bosch fuel pump generally used for diesel fuel injection in truck engines coupled to a variable electric drive. A high-speed electrical mixing chamber facilitated thorough emulsification. The test rig facilitated the independent variation of the injection pressure $(\mathrm{p})$ the frequency of injection $(\mathrm{N})$ and the rate of injection $(\mathrm{Q})$. The system can deliver fluids through six outlets simultaneously, so that cutting fluid could be injected to more than one location or more than one machine tool at the same time. By selecting proper settings, the rate of injection could be made as small as $0.5 \mathrm{ml} / \mathrm{min}$. Special fixtures were designed, so that the injection nozzle could be located in any desired position without interfering with the tool or work during actual cutting.

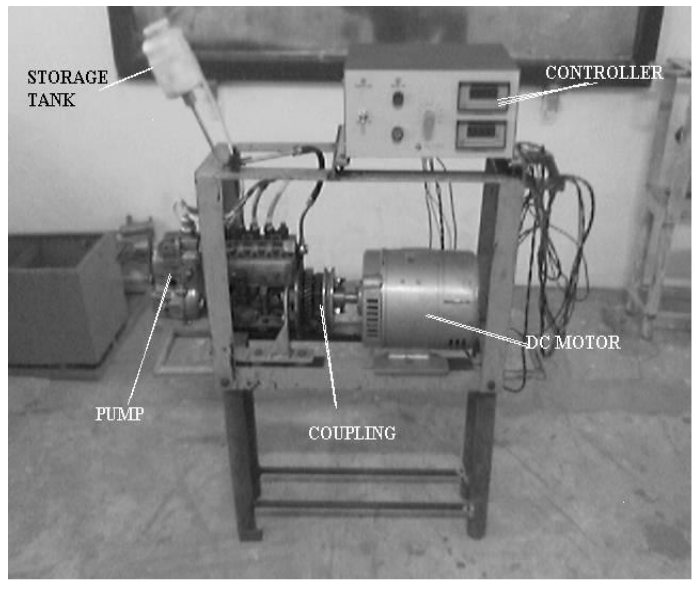

Fig 4.6 Fluid application system (Fabricated)

\subsubsection{INJECTOR WORKING PRINCIPLE}

When the fuel is supplied by the injection pump it exerts sufficient force against the spring to lift the nozzle valve, fuel is sprayed. After, fuel from the delivery pump gets exhausted; the spring pressure pushes the nozzle valve back on its seat. For proper lubrication between nozzle valve and its guide of fuel is allowed to leak through the clearance between them and then drained back to fuel tank through leak off connection. The spring tension and hence the valve opening pressure is controlled by the adjusting the screw provided at the top. A cross sectional view of the injector is shown in Fig. The injector used in experiment setup is off berkins make.

The injectors used for injecting the coolant at high pressure are same that used in motor cars. The injector has a special feature to control the output pressure by adjusting a screw mechanism at the rear end of the injector. The front end of the injector has the nozzle. It converts high pressure of fluid to high velocity so that it can reach at the point of heat generation when cutting takes place.

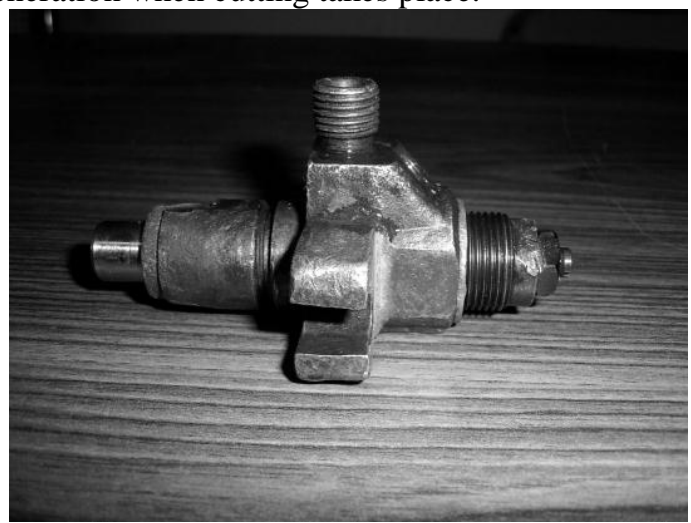

Fig 4.7 Injector 
DN OSD 151-spary angle of $0^{0}$ which produces a pulsed slug of cutting fluid. Cutting fluid is applied in the form of slugs. Fluid is delivered in the form of slugs using a nozzle of zero divergence to improved cutting performance

\subsubsection{NOZZLE TESTER}

It is a device used to test the injector. It is also used to set the pressure of the injector. It has a coolant tank at the rear side of it. There is a handle at the front end, which is used to crank it to high pressure. There is a dial gauge fixed at the top of the device. It will show the pressure of outlet when we crank it using the handle. The figure of the nozzle tester is shown below.

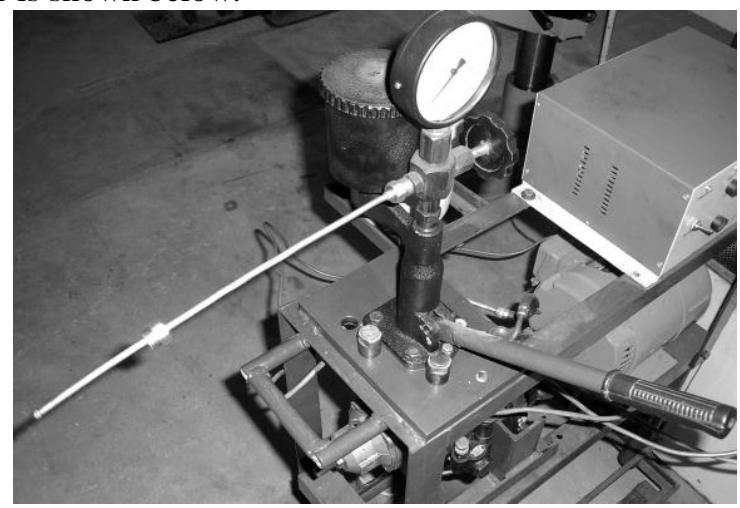

Fig 4.8 Nozzle tester

\section{Results And Discussions}

Minimum quantity lubrication (MQL) presents itself as a viable alternative for hard machining with respect to tool wear, heat dissipation, and machined surface quality have to be proven with the help of the experimentation. Metal cutting fluids changes the performance of machining operations because of their lubrication, cooling, and chip flushing functions. Typically, in the machining of hardened steel materials, no cutting fluid is applied in the interest of low cutting forces and low environmental impacts. This study compares the mechanical performance of minimum quantity lubrication to completely dry lubrication for the turning of hardened steel materials(with $40 \mathrm{HRC}$ ) based on experimental measurement of cutting forces, tool wear, chip characteristics, tool temperature and surface finish.

The results of these experiments are in the form of Taguchi's chart and graphs. These are used for comparing the results. There are first set of readings and its replication. The results are of values of surface finish, tool wear, cutting force and cutting temperature.

\subsection{FIRST SET EXPERIMENTATION RESULTS}

The effects of the cutting parameters on the surface roughness, cutting force, tool wear, tool chip contact length, emf value and acceleration are shown in following figures. According to the principle of design of experiment, presence of direction of cutting fluid application in single jet, multiple jet and flood cooling. In this experiment surface finish, cutting force, tool wear and cutting temperature is the dominant factor among the cutting conditions followed by the quality of coolant. But we can't finalize these results because some errors might happen during measurements. After analyzing the replication results we can conclude the exact cutting parameters which are dominant effect on cutting conditions.

\subsubsection{SURFACE FINISH $(\mu \mathrm{m})$}

The effects of the cutting parameters on the surface roughness are shown in this table. The cutting velocity of $100 \mathrm{~m} / \mathrm{min}$, feed of $0.1 \mathrm{~mm} / \mathrm{rev}$, depth of cut of $0.8 \mathrm{~mm}$ and multiple jet are giving good surface finish values. But we can't finalize these results because some errors might happen during measurements. After analyzing the replication results we can conclude the exact parameters which are dominant effects on the cutting conditions. Graphical representation of surface finish by the cutting parameters is shown below. 


\section{SURFACE FINISH}

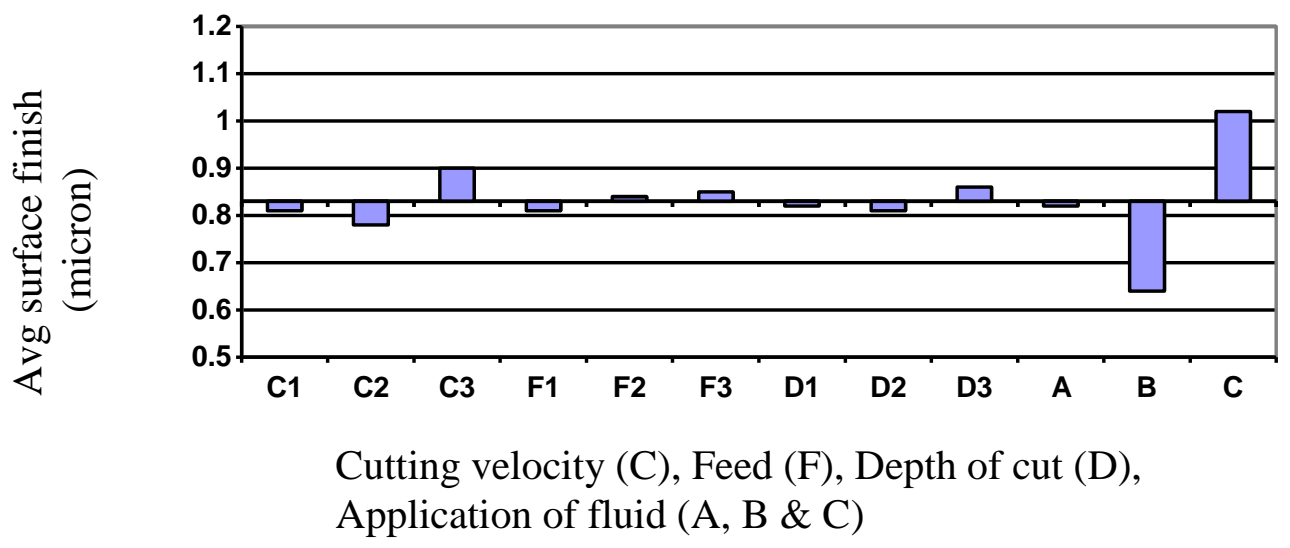

Fig: 6.1 Graphical representation of surface finish

\subsubsection{CUTTING FORCE (N)}

\section{TABLE 6.2 CUTTING FORCE}

The effects of the cutting parameters on the cutting force are shown in this table. The cutting velocity of $100 \mathrm{~m} / \mathrm{min}$, feed of $0.1 \mathrm{~mm} / \mathrm{rev}$, depth of cut of $0.8 \mathrm{~mm}$ and multiple jet are giving less cutting force values. But we can't finalize these results because some errors might happen during measurements. After analyzing the replication results we can conclude the exact parameters which are dominant effects on the cutting conditions. Graphical representation of cutting force by the cutting parameters is shown below.
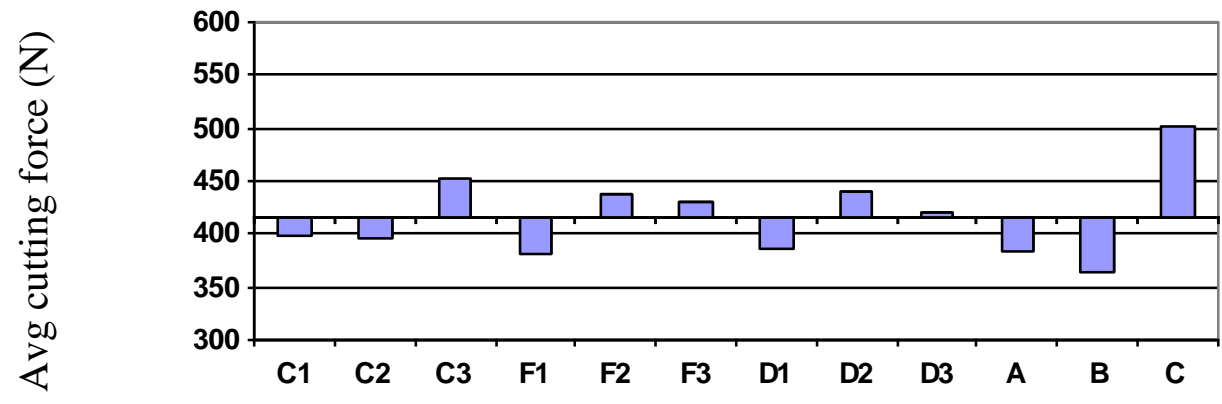

Cutting velocity (C), Feed (F), Depth of cut (D),

\subsubsection{TOOL WEA Application of fluid (A, B \& C)}

The effecıs or une cuung parameters on me tooı wear are snown in uns labıe. i he cutting velocity of $80 \mathrm{~m} / \mathrm{min}$, feed of $0.1 \mathrm{~mm} / \mathrm{rev}$, depth of cut of $1.2 \mathrm{~mm}$ and multiple jet are giving less tool wear values. But we can't finalize these results because some errors might happen during measurements. After analyzing the replication results we can conclude the exact parameters which are dominant effects on the cutting conditions. Graphical representation of tool wear by the cutting parameters is shown below. 
TABLE 6.3 TOOL WEAR

TOOL WEAR

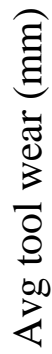

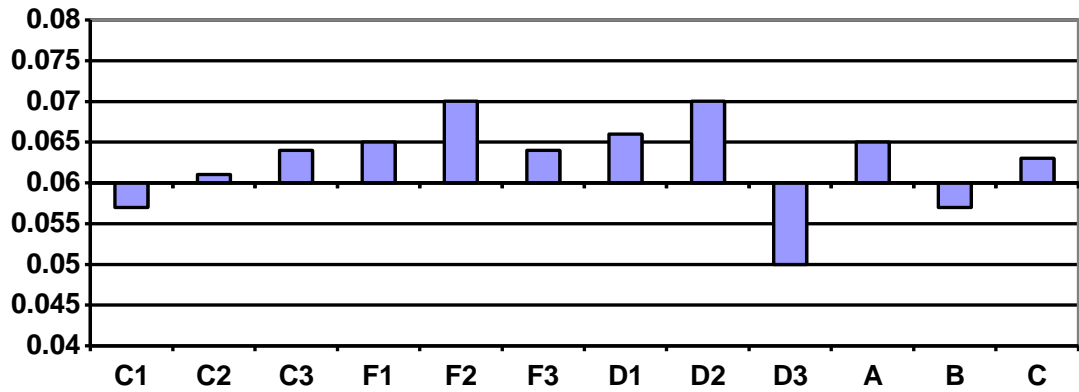

Cutting velocity (C), Feed (F), Depth of cut (D), Application of fluid (A, B \& C)

Fig: 6.3 Graphical representation of tool wear

\subsubsection{EMF VALUES (mv)}

\section{TABLE 6.4 EMF VALUES}

The effects of the cutting parameters on the emf value are shown in this table. The cutting velocity of $120 \mathrm{~m} / \mathrm{min}$, feed of $0.14 \mathrm{~mm} / \mathrm{rev}$, depth of cut of $0.8 \mathrm{~mm}$ and flood cooling giving less emf values. But we can't finalize these results because some errors might happen during measurements. After analyzing the replication results we can conclude the exact parameters which are dominant effects on the cutting conditions. Graphical representation of emf value by the cutting parameters is shown below.

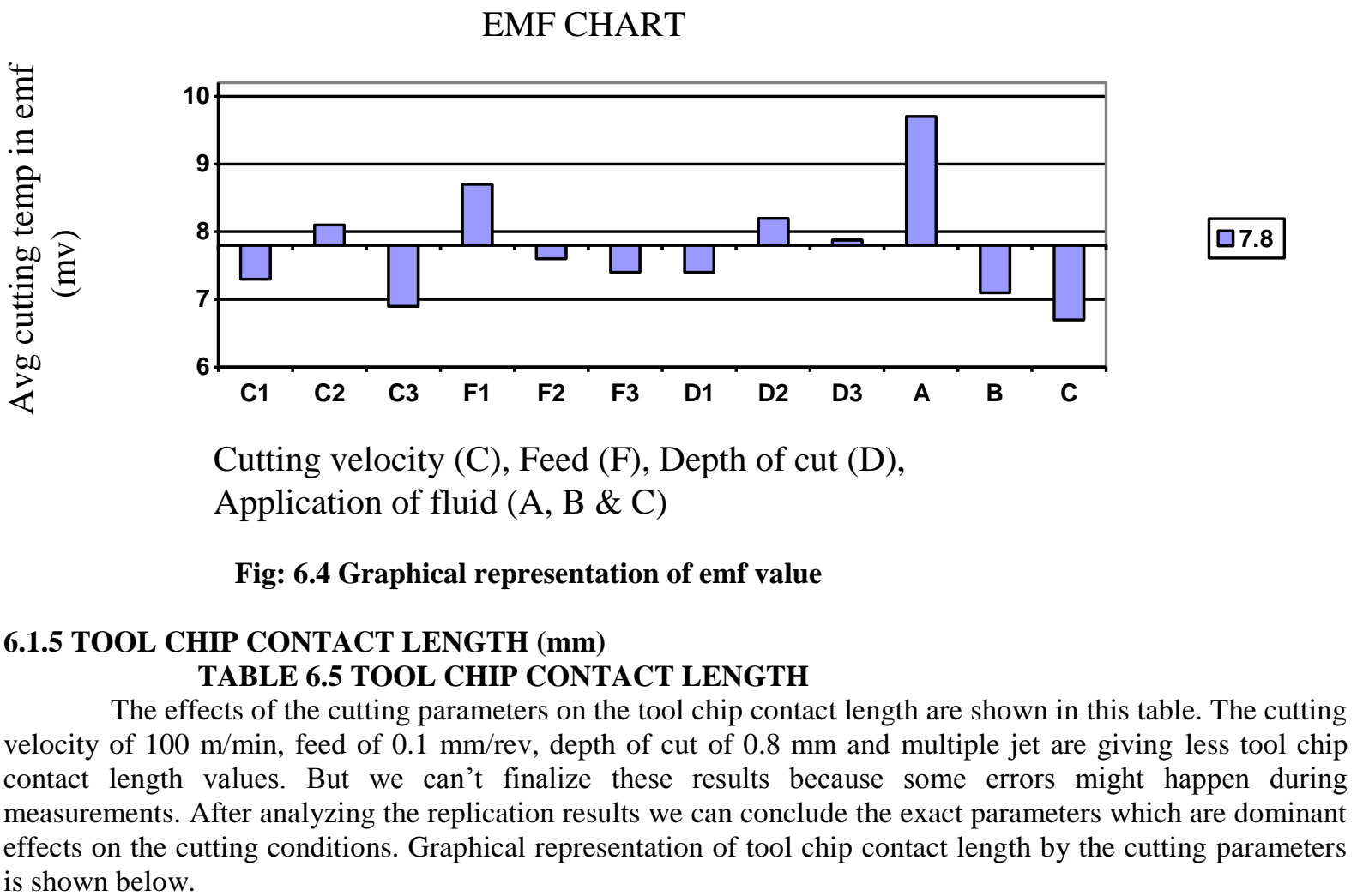


TOOL CHIP CONTACT LENGTH
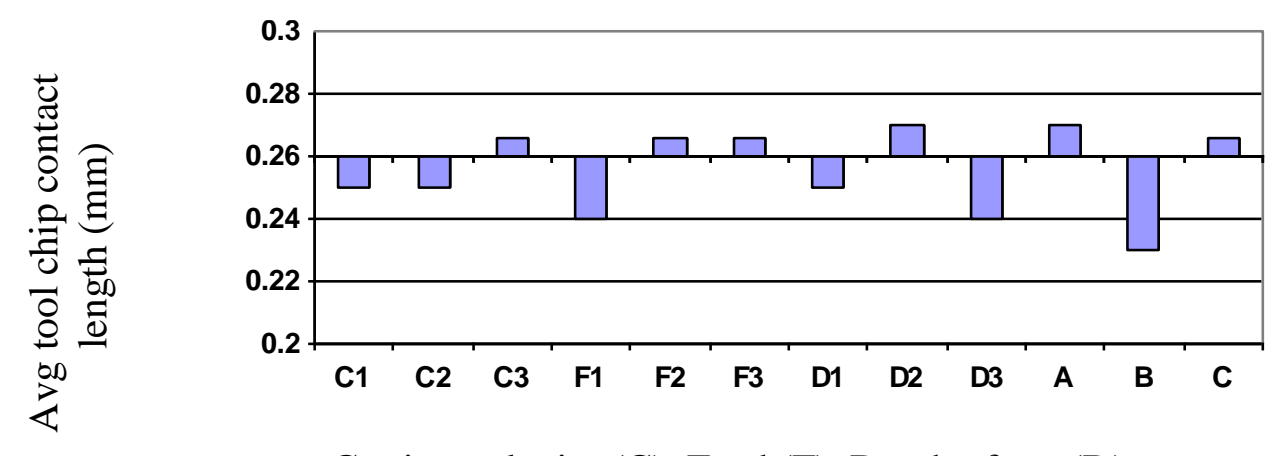

Cutting velocity (C), Feed (F), Depth of cut (D), Application of fluid (A, B \& C)

Fig: 6.5 Graphical representation of tool chip contact length

\subsection{REPLICATION RESULTS FOR THE EXPERIMENT 6.2.1 SURFACE FINISH $(\boldsymbol{\mu} \mathrm{m})$}

TABLE 6.7 SURFACE FINISH

When cutting velocity is high as $120 \mathrm{~m} / \mathrm{min}$, the chip makes fully plastic or bulk contact with the tool rake surface and prevents any fluid from entering into the hot chip- tool interface. When cutting velocity is low and feed is high, the chip- tool contact is partially elastic. So, when cutting velocity is $100 \mathrm{~m} / \mathrm{min}$, feed $0.1 \mathrm{~mm} / \mathrm{rev}$, depth of cut $0.8 \mathrm{~mm}$ and with multiple jets gives good surface finish. The replication table and graph is shown.

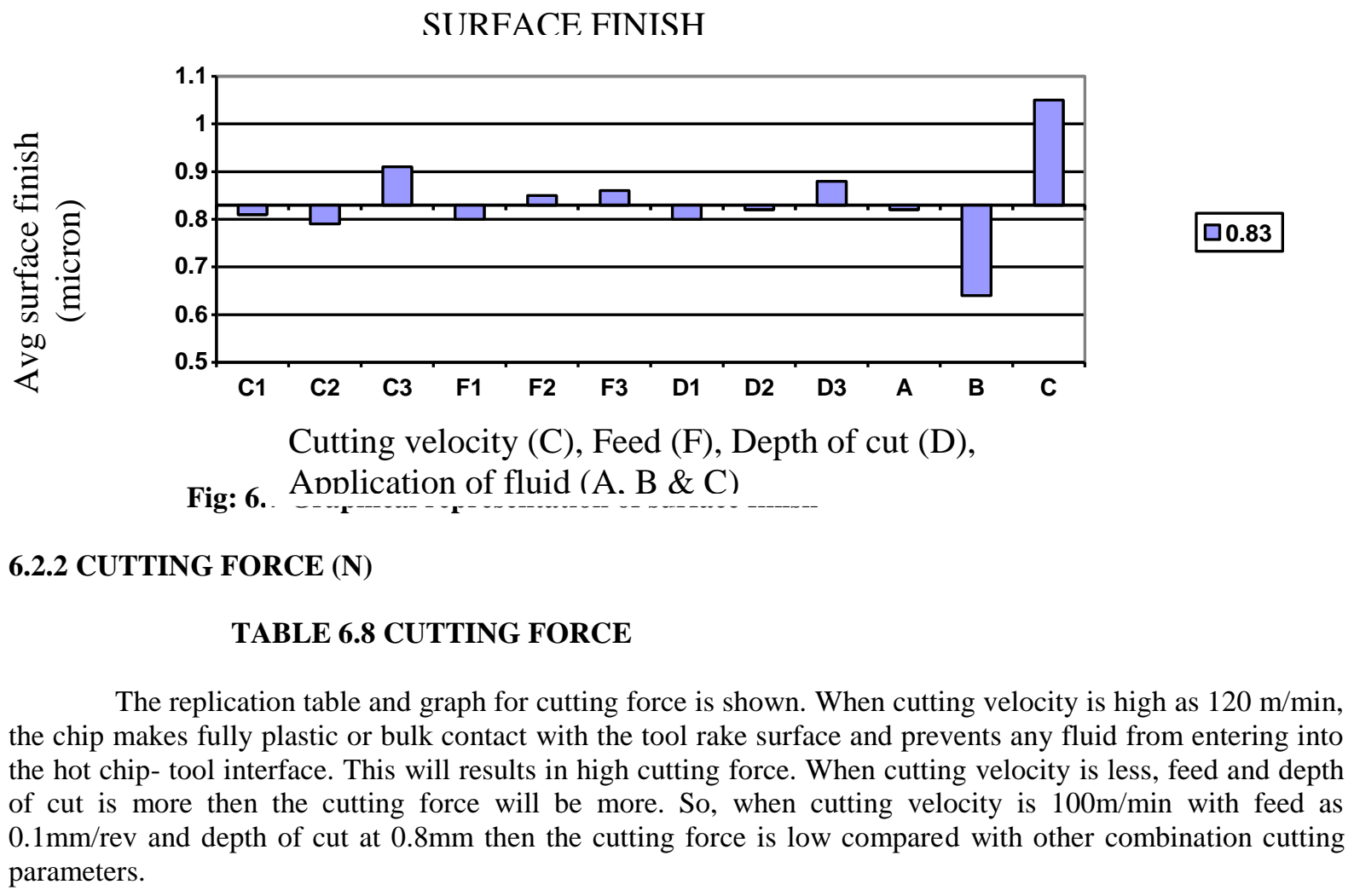




\section{CUTTING FORCE}

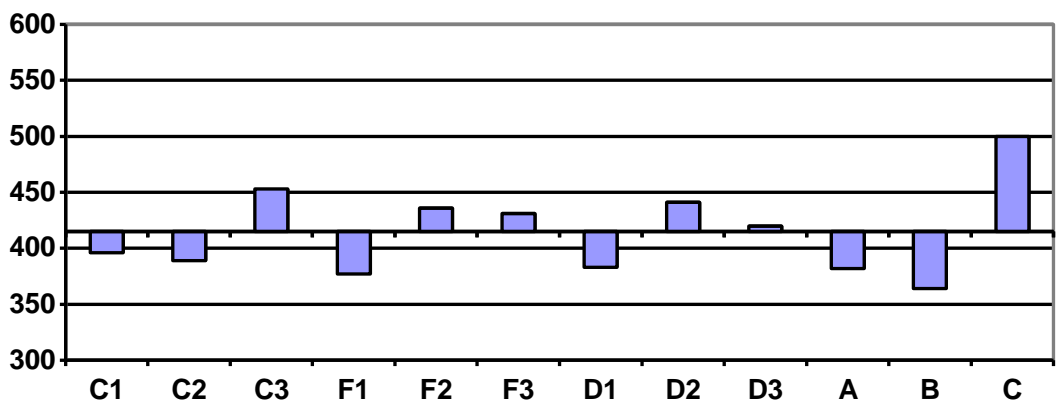

Cutting velocity (C), Feed (F), Depth of cut (D), Application of fluid (A, B \& C)

Fig: 6.8 Graphical representation of cutting force

\subsubsection{TOOL WEAR (mm)}

The replication table and graph for tool wear is shown. When cutting velocity is high as $120 \mathrm{~m} / \mathrm{min}$, the chip makes fully plastic or bulk contact with the tool rake surface and prevents any fluid from entering into the hot chip- tool interface. This will results in high cutting force. When cutting force increases the tool wear will also increases and tool life will be reduced. When cutting velocity is less, feed and depth of cut is more then the cutting force will be more. So, when cutting velocity is $100 \mathrm{~m} / \mathrm{min}$ with feed as $0.1 \mathrm{~mm} / \mathrm{rev}$ and depth of cut at $0.8 \mathrm{~mm}$ then the tool wear is low compared with other combination cutting parameters.

\section{TABLE 6.9 TOOL WEAR}

TOOL WEAR

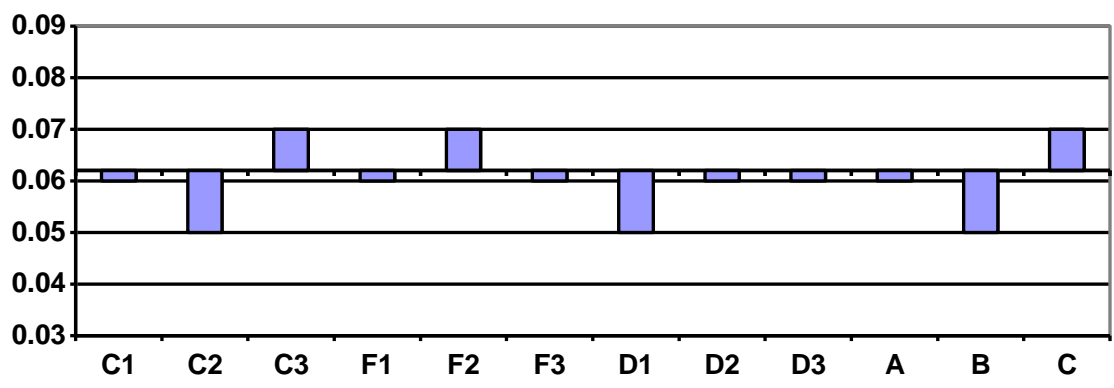

Cutting velocity (C), Feed (F), Depth of cut (D), Application of fluid (A, B \& C)

Fig: 6.9 Graphical representation of tool wear

\subsubsection{EMF VALUES (mv)}

The replication table and graph for emf value is shown. Multiple jet cooling effect also improved to some extent with the decrease in feed particularly at lower cutting velocity. Possibly, the thinner chips, especially at lower chip velocity, are slightly pushed up the high pressure MQL jet coming from the opposite direction and enable it to come closer to the hot chip tool contact zone to remove heat more effectively. Further, at high velocity, the coolant may not get enough time to remove the heat accumulated at the cutting zone resulting in less reduction in temperature. So, when cutting velocity is $100 \mathrm{~m} / \mathrm{min}$ with feed as $0.1 \mathrm{~mm} / \mathrm{rev}$ and depth of cut at $0.8 \mathrm{~mm}$ then the emf value is low compared with other combination cutting parameters. 


\section{EMF CHART}
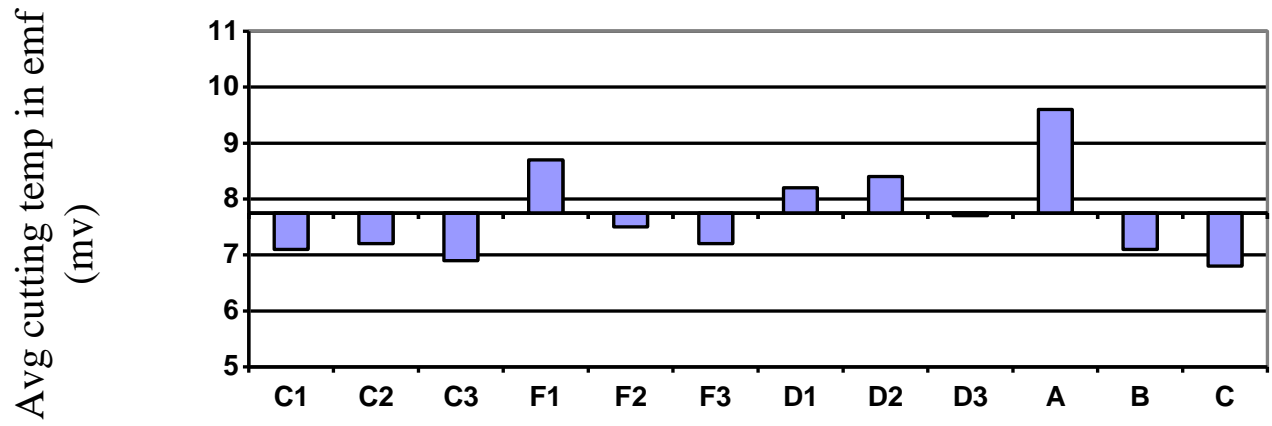

Cutting velocity (C), Feed (F), Depth of cut (D), Application of fluid (A, B \& C)

Fig: 6.10 Graphical representation of emf value

\subsubsection{TOOL CHIP CONTACT LENGTH (mm)}

The replication table and graph for tool chip contact length is shown. When cutting velocity is high as $120 \mathrm{~m} / \mathrm{min}$, the chip makes fully plastic or bulk contact with the tool rake surface and prevents any fluid from entering into the hot chip- tool interface. This will results in high cutting force. When cutting force increases the tool wear will also increases and tool life will be reduced. When cutting velocity is less, feed and depth of cut is more then the cutting force will be more. So, when cutting velocity is $100 \mathrm{~m} / \mathrm{min}$ with feed as $0.1 \mathrm{~mm} / \mathrm{rev}$ and depth of cut at $0.8 \mathrm{~mm}$ then the tool chip contact length is low compared with other combination cutting parameters.

\section{Conclusion}

This project mainly concern with the minimal quantity lubricant used in metal cutting process during turning operation. New cutting techniques are to be investigating to achieve this objective. Hard turning with minimal fluid application is one such technique, which can ease the pollution problems associated with cutting fluids. In this project specially formulated cutting fluid is applied at high velocity, thin pulsed multiple jet form at the immediate cutting zones at extremely low rate of $5 \mathrm{ml} / \mathrm{min}$. Objective of this project is to enhance the performance of conventional hard turning by the application of minimal multiple jet of cutting fluid and compare it with conventional wet and pure dry cutting with respect to surface finish, tool wear and tool life.

A detailed literature survey regarding the thesis was carried out. It was found from the literatures that turning with minimal multiple jet of cutting fluid application system improves surface finish, reduces tool wear and increase tool life.. Accordingly the Design of experiment was carried out. The input and output parameters were identified. The fluid application system was fabricated. After done the nine run experiment, hard turning with minimal multiple jet of cutting fluid is the better result to compare the single jet, dry and wet turning only quantity is $5 \mathrm{ml} / \mathrm{min}$ is used to improve the surface finish, reduce tool wear under optimized cutting parameters.

When cutting velocity is high as $120 \mathrm{~m} / \mathrm{min}$, the chip makes fully plastic or bulk contact with the tool rake surface and prevents any fluid from entering into the hot chip- tool interface. This will results in high cutting force. When cutting velocity is less, feed and depth of cut is more then the cutting force will be more. Multiple jet cooling effect also improved to some extent with the decrease in feed particularly at lower cutting velocity. Possibly, the thinner chips, especially at lower chip velocity, are slightly pushed up the high pressure MQL jet coming from the opposite direction and enable it to come closer to the hot chip tool contact zone to remove heat more effectively. Further, at high velocity, the coolant may not get enough time to remove the heat accumulated at the cutting zone resulting in less reduction in temperature. So, when cutting velocity is $100 \mathrm{~m} / \mathrm{min}$ with feed as $0.1 \mathrm{~mm} / \mathrm{rev}$ and depth of cut at $0.8 \mathrm{~mm}$ then the cutting force is low compared with other combination cutting parameters.

The cutting performance of MQL machining is better than that of dry and conventional machining with flood cutting fluid supply because MQL provides the benefits mainly by reducing the cutting temperature, which improves the chip-tool interaction and maintains sharpness of the cutting edges. MQL jet provided reduced tool wear, improved tool life and better surface finish as compared to dry and wet machining of steel. Surface finish and dimensional accuracy improved mainly due to reduction of wear and damage at the tool tip 
by the application of MQL. Such reduction in tool wear would either lead to improvement in tool life or enhancement of productivity allowing higher cutting velocity and feed.

\section{References:}

[1]. A.S .Varadarajan, P.K. Philip and B. Ramamoorthy, (1999) "Investigations on hard turning with minimal pulsed jet of cutting fluid", International seminar on manufacturing technology beyond 2000, Bangalore, November 17, pp.173.

[2]. A.S Varadarajan, P.K. Philip and B. Ramamoorthy, (2002) "Investigations on hard turning with minimal cutting fluid application(HTMF) and its comparison dry and wet turning", International journal of machine tools \& manufacture , vol 42, pp. 193200 .

[3]. P.K. Philip, A.S. Varadarajan, B. Ramamoorthy, (2000) "Influence of cutting fluid composition and delivery variables on performance in hard turning using minimal fluid in pulsed jet form", journal of the institution of engineers -India.

[4]. Nikhil Ranjan Dhar, Sumaiya Islam, Mohammad Kamruzzaman, (2007) "Effect of minimal quantity lubrication on tool wear, surface roughness and dimensional deviation in turning AISI-4340 steel", G.U. Journal of science, vol 20(2), pp.23-32.

[5]. Dhar. N.R., Islam. M.W., Islam. S., Mithu. M.A.H., (2006) "The influence of minimal quantity of lubrication (MQL) on cutting temperature, chip and dimensional accuracy in turning AISI-1040 steel”, Journal of materials processing technology, vol 171, pp-9399.

[6]. A. Attanasio, M. Gelfi, C. Giardini, C. Remino, (2005) "Minimal quantity lubrication in turning: Effect on tool wear", Wear vol 260, pp-333-338.

[7]. Anselmo Eduardo Diniz, Ricardo Micaroni, (2006) "Influence of the direction and flow rate of the cutting fluid on tool life in turning process of AISI-1045 steel”, International journal of machine tools and manufacture, vol.44, pp-1067-1077. 